\title{
TINGKAT ADOPSI PETANI HIDROPONIK MENDUKUNG AGROPOLITAN DI KOTA TARAKAN (STUDI KASUS DI KECAMATAN TARAKAN TENGAH)
}

\section{HYDROPONIC FARMER ADOPTION RATE SUPPORTS AGROPOLITAN IN THE CITY OF TARAKAN (CASE STUDY IN CENTRAL TARAKAN DISTRICT)}

\author{
Sekar Inten Mulyani' ${ }^{1}$, Sofea ${ }^{2}$ \\ 1) 2) Fakultas Pertanian, Universitas Borneo Tarakan \\ Email: ${ }^{1}$ sekar@borneo.ac.id
}

\begin{abstract}
ABSTRAK
Hidroponik menjadi inovasi di Kota Tarakan sejak Tahun 2010 melalui program CSR yang dilakukan Pertamina. Seiring perjalanan waktu perkembangan adopsi teknik hidroponik mengalami perlambatan hal ini diakibatkan oleh Skill yang kurang dan minat yang menurun Selain itu teknologi hidroponik juga membutuhkan biaya dan modal yang lumayan banyak karena alat-alat hidroponik cukup mahal. Penelitian ini bertujuan untuk: 1) Mengetahui proses adopsi inovasi teknologi hidroponik yang dilakukan oleh Petani Hidropoik; 2). Menganalisis tingkat adopsi petani terhadap teknologi hidroponik di Kota Tarakan dan 3). Menganalisis faktor-faktor apa saja yang mempengaruhi tingkat adopsi petani Hidroponik. Penelitian ini dilaksanakan pada bulan Agustus sampai dengan September 2020 dengan mengambil 39 responden. Metode analisis yang digunakan menggunakan metode deskriptif kuantitatif dengan bantuan SPSS 18.00. Adapun proses proses adopsi melalui beberapa tahapan yaitu Kesadaran (awareness), Tahap minat (Interest), Tahap penilaian (Evaluation), Tahap mencoba (Trial), Tahap adopsi (Adoption). Tingkat adopsi petani dalam kategori tinggi $(49 \%)$, sedang $(46 \%)$ dan rendah $(5 \%)$. Faktor-faktor yang mempengaruhi tingkat adopsi dapat dituliskan dalam persamaan:

$\mathrm{Y}=9,938+1,066 \times 1+2,766 \times 2+1,370 \times 3+0,729 \times 4+e, \quad$ dimana, $\times 1=$ umur,$\times 2=$ tingkat pendidikan, $\times 3=$ lama hidroponik dan $\times 4=$ pendapatan. Koefisien regresi sebesar $\mathrm{R} 2=$ $58,6 \%$, uji t menunjukkan dari ke empat variabel $\times 1, \times 2$ dan $\times 3$ signifikan $(\operatorname{sig}<0,05)$ sedangkan $\times 4$ tidak signifikan ( $\operatorname{sig}>0,05)$.
\end{abstract}

\section{Kata Kunci: Adopsi, Petani, Hidroponik}

\begin{abstract}
Hydroponics has been an innovation in Tarakan City since 2010 through Pertamina's CSR program. Over time, the development of the adoption of hydroponic techniques has slowed down, this is due to lack of skills and decreased interest. In addition, hydroponic technology also requires a lot of money and capital because hydroponic tools are quite expensive. This study aims to: 1) Knowing the hydroponic technology innovation adoption process carried out by hydropoic farmers; 2). Analyzing the level of farmer adoption of hydroponic technology in Tarakan City and 3). Analyze what factors affect the level of hydroponic farmer adoption. This research was conducted from August to September 2020 by taking 39 respondents. The method of analysis used is descriptive quantitative method with the help of SPSS 18.00. The adoption process goes through several stages, namely Awareness, Interest, Evaluation, Trial, Adoption. The adoption rate of farmers was in the high (49\%), medium (46\%) and low (5\%) categories. The factors that influence the adoption rate can be written in the equation:

$Y=9,938+1,066 \times 1+2,766 \times 2+1,370 \times 3+0,729 \times 4+e$, where, $x 1=$ age, $x 2=$ education level, $x 3=$ hydroponic duration and $x 4=$ income. The regression coefficient is
\end{abstract}


$R 2=58.6 \%$, the $t$ test shows that the four variables $x 1, x 2$ and $x 3$ are significant (sig $<0.05$ ) while $x 4$ is not significant (sig>0.05).

\section{Keywords: Adoption, Farmers, Hydroponics}

\section{PENDAHULUAN}

Program CSR yang dilakukan Pertamina di kelompok tani Kampung Satu Kota Tarakan. Budidaya dengan teknik hidroponik menghasilkan sayuran seperti sawi dan selada. Pada awal pengenalan hidroponik, minat petani di Kota Tarakan untuk melaksanakan budidaya tanaman sayuran dengan teknik hidroponik berkembang cukup baik. Hal ini terlihat dari semakin banyak terbentuk kelompok tani dan komunitas komunitas yang membudidayakan sayuran secara hidroponik yanag tersebar di beberapa Kecamatan Di Kota Tarakan. Selain dari CSR perusahaan ,penyuluhan dan pendampingan inovasi hidroponik juga dilakukan oleh Dinas Pertanian Kota Tarakan di beberapa kelompok petani Binaannya. Hal ini mendukung agropolitan di Kota Tarakan, selain kota jasa dan perdagangan Kota Tarakan juga memiliki potensi sebagai agropolitan. Tujuan dari pengembangan kawasan agropolitan ini adalah untuk meningkatkan pendapatan dan kesejateraan masyarakat melalui percepatan pengembangan wilayah dan peningkatan keterkaitan desa dan kota dengan mendorong berkembangnya sistem dan usaha agribisnis yang berdaya saing, berbasis kerakyatan, berkelanjutan dan terdesentralisasi di kawasan agropolitan (Suroyo, 2014). Tujuan Penelitian ini adalah :1) Mengetahui proses adopsi inovasi teknologi hidroponik yang dilakukan oleh Petani Hidropoik;2) Menganalisis tingkat adopsi petani terhadap teknologi hidroponik di Kota Tarakan dan 3) Menganalisis faktorfaktor apa saja yang mempengaruhi tingkat adopsi petani Hidroponik.

\section{METODE PENELITIAN \\ Lokasi dan Waktu}

Penelitian ini dilaksanakan di Kota Tarakan mengambil studi kasus di Kecamatan Tarakan Tengah. Tarakan Tengah dipilih sebagai lokasi penelitian karena terdapat 7 Kelompok Tani Hidroponik serta inovasi hidroponik tersebut pertama kali dikenalkan pada petani di Kecamatan tersebut. Penelitian dilaksanakan Bulan Juli sampai dengan September 2020.

\section{Metode Penentuan Sampel}

Metode penentuan sampel yang digunakan dalam penelitian ini adalah metode Quota sampling. Menurut Sugiyono (2013) Quota sampling adalah teknik untuk menentukan sampel dari populasi yang memiliki ciri-ciri tertentu sampai jumlah (kuota) yang diinginkan. Responden yang diambil sebanyak 39 responden yang dipilih sebagai petani hidroponik di Kecamatan Tarakan Tengah yang telah mengikuti penyuluhan tentang hidroponik.

\section{Metode Analisis Data}

Statistik deskriptif digunakan untuk menganalisis tujuan pertama yaitu untuk mengetahui proses adopsi inovasi teknologi hidroponik. Untuk mengetahui tujuan kedua yaitu tingkat adopsi petani hidroponik dengan menggunakan analisis kuantitatif dengan menggunakan Skala Likert. Berdasarkan jawaban responden pada kuesioner diperoleh data untuk kemudian di analisis dengan metode skoring (skor). indikator terdapat tiga pertanyaan dengan skor minimal 1 dan skor maksimal 3 (rendah,cukup dan tinggi). Analisis regresi digunakan untuk menganalisis faktor-faktor apa saja yang mempengaruhi adopsi inovasi petani hidroponik dilihat dari karakteristik petani, dengan bantuan SPSS 18.00 dengan menggunakan uji t dan uji $F$.

\section{HASIL DAN PEMBAHASAN

Proses Adopsi Inovasi Petani
Hidroponik

Kota Tarakan meskipun kota perdagangan dan bisnis, namun sektor pertanian juga masih terlihat dibudidayakan petani. Keterbatasan 
JURNAL BORNEO SAINTEK

Volume 3, Nomor 2, Oktober 2020

e-ISSN 2599-3313

P-ISSN 2615-434X
Available online at www.jurnal.borneo.ac.id Halaman 79-83 lahan dan struktur tanah yang berpasir, menyebabkan beberapa petani memilih bertani dengan hidroponik. Sistem pertanian agropolitan menjadi pilihan petani di kota Tarakan untuk mendukung ketahanan pangan. Agropolitan adalah kota pertanian yang tumbuh dan berkembang seiring berjalannya sistem dan usaha agribisnis yang mampu melayani, mendorong, menarik, dan menghela kegiatan pembangunan pertanian (agribisnis) wilayah sekitarnya (Suwandi, 2005 dalam Iqbal 2009). Sejak tahun 2010 petani di kota Tarakan telah dikenalkan dengan sistem hidroponik. Tidak semua petani mengadopsi hidroponik, beberapa penyebab baik secara internal (karakteristik petani) dan ekternal (sifat inovasi) yang mempengaruhi petani mengadopsi inovasi. Adopsi merupakan proses penerimaan inovasi dan atau perubahan perilaku baik yang berupa pengetahuan, sikap, maupun ketrampilan pada diri seseorang setelah menerima inovasi yang disampaikan penyuluh ke masyarakat sasarannya (Harnanik, 2014). Adapun proses adopsi inovasi petani hidroponik meliputi : Proses adopsi melalui beberapa tahapan yaitu Kesadaran (awareness), Tahap minat (Interest), Tahap penilaian (Evaluation), Tahap mencoba (Trial), Tahap adopsi (Adoption).

\section{Tahap Kesadaran (awareness)}

Petani yang ada dikecamatan Tarakan Tengah mulai menyadari adanya suatu inovasi hidroponik yang dimana dalam penelitian ini ada 39 responden sadar akan pentingnya suatu inovasi persentase $100 \%$. Dalam hal ini petani di Kecamatan Tarakan Tengah mulai terbuka akan perkembangan inovasi hidroponik contohnya mereka sering mengikuti penyuluhan tentang hidroponik yang diadakan oleh Dinas Pertanian Tanaman Pangan dan Peternakan Kota Tarakan. Beberapa petani mencari sumber-sumber informasi mengenai perkembangan hidroponik melalui youtube, sosial media.

Kesadaran mereka akan teknik budidaya hidroponik setelah mengetahui manfaat sayuran hidroponik yang rendah unsur kimia dan dapat ditanam dilahan yang sempit.

\section{Tahap minat (interest)}

Petani yang ada di Kecamatan Tarakan Tengah memiliki minat yang cukup tinggi dimana dalam penelitian ini ada 39 responden dan yang minat akan pentingnya inovasi hidroponik ini sekitar 37 orang dengan persentase $95 \%$. Setelah mereka mengikuti penyuluhan tentang hidroponik dalam hal ini timbul rasa minat petani yang ada di Kecamatan Tarakan Tengah untuk mencari tahu tentang hidroponik, mulai dari cara berhidroponik, mencari jenis- jenis hidroponik hingga cara menangani hidroponik dan lain-lain

\section{Tahap penilaian (Evaluation)}

Tahap penilaian ini merupakan tahap menilai apakah inovasi hidroponik ini baik atau tidak untuk dilakukan oleh petani di Kecamatan Tarakan Tengah yang sudah mulai dalam tahap minat untuk melakukan inovasi hidroponik tersebut. Petani menilai bahwa hidroponik ini sangat bagus, karna hidroponik ini sangat mudah untuk dilakukan di perkarangan rumah yang kecil, Hidroponik mudah untuk dirawat dan tidak membutuhkan tenaga yang banyak (besar), bisa juga menjadi suatu hobi atau sampingan buat ibu- ibu rumah tangga yang tidak memiliki pekerjaan diluar rumah dan sangat menguntungkan dalam segi ekonomi.

\section{Tahap mencoba ( trial)}

Tahap mencoba yaitu tahap dimana yang sedang dijalani oleh petani hidroponik di Kecamatan Tarakan Tengah sekita ada 39 responden dengan persentase $100 \%$ petani. Setelah menilai petani mulai mencoba dengan pertimbangan yang apabila hasil yang mereka dapatkan positif atau mereka telah berhasil mencoba maka mereka akan terus melanjutkan hidroponiknya. Contohnya setelah mereka mendapatkan penyuluhan mereka langsung mencoba mengaplikasikannya dirumah dengan mengggunakan bahan - bahan bekas yang ada disekitar rumah. 
JURNAL BORNEO SAINTEK

Volume 3, Nomor 2, Oktober 2020

e-ISSN 2599-3313

P-ISSN 2615-434X

\section{Tahap adopsi (adoption)}

Secara keseluruhan ada 39 responden dengan persentase $100 \%$ Petani hidroponik di Kecamatan Tarakan Tengah masih termasuk orang yang baru melakukan hidroponik dalam tahapan mencoba suatu inovasi tersebut. Tetapi ada beberapa petani juga yang sudah lama menjalankan hidroponik dan sudah memiliki hasil yang baik dalam hal ini petani yang ada di Kecamatan Tarakan Tengah sangat menerima akan adanya suatu inovasi baru yaitu hidroponik.
Available online at www.jurnal.borneo.ac.id Halaman 79-83

Tabel 1. Tingkat Adopsi Petani Hidroponik

\begin{tabular}{llll}
\hline No & Tingkat Adopsi & Frekuensi (orang) & Persentase (\%) \\
\hline 1 & Rendah & 2 & 5 \\
2. & Sedang & 18 & 46 \\
3. & Tinggi & 19 & 49 \\
& Jumlah & 39 & 100 \\
\hline
\end{tabular}

Sumber: Data Primer, 2020

Berdasarkan tabel 1 menunjukkan mayoritas tingkat adopsi petani hidroponik dalam kategori tinggi sebesar $49 \%$. Tinggi nya tingkat adopsi petani dikarenakan petani hidroponik berada di usia produktif, dan berpendidikan ratarata SMA,sehingga mereka lebih mudah menerima inovasi yang ditawarkan dan mengadopsinya dengan baik. Hal ini sesuai dengan pendapat Wangke (2016) yang menyatakan terdapat hubungan antara tingkat umur,pendidikan, luas kepemilikan lahan dan pendapatan. Umur

\section{Tingkat Adopsi Petani Hidroponik}

Tingkat Adopsi petani hidroponik digunakan untuk menganalisis sejauh mana tingkatan adopsi petani yang telah mendapatkan inovasi tentang budidaya hidroponik. Tingkat adopsi petani dengan menggunakan tiga parameter yaitu pengetahuan, sikap dan keterampilan petani, dengan skala likert diperoleh kategori tingkat adopsi mulai dari rendah (skor 9 -15) ) sedang (skor 16 - 21) dan tinggi (skor 22 - 27). Berikut tabel tingkat adopsi petani hidroponik.

Tabel 2. Analisis Regresi Linier Berganda

\begin{tabular}{llll}
\hline No & \multicolumn{1}{c}{ Uraian } & Koefisien & Signifikan \\
\hline 1 & Constant & 9,938 & 0,00 \\
2 & X1 (umur) & 1,066 & 0,016 \\
3 & x2(tingkat pendidikan) & 2,766 & 0,000 \\
4 & x3(lama berhidroponik) & 1,370 & 0,015 \\
5 & X4(pendapatan) & 0,729 & 0,129 \\
6 & Uji F (Anova) & & 0,000 \\
7 & Koefisien Determinasi $\left(\mathrm{R}^{2}\right)$ & 0,586 & \\
\hline
\end{tabular}

Sumber: Data Primer, 2020

Hasil uji regresi linier berganda menyatakan bahwa dari keempat faktor yang mempengaruhi tingkat adopsi petani secara parsial, hanya satu variabel yang tidak signifikan yaitu $x 4$ (pendapatan) karena nilai signifikansi > 0,05 . Secara bersama-sama variabel independent $(X)$ berpengaruh secara muda, pendidikan lebih tinggi,pemilikan lahan luas, pendapatan tinggi cenderung tingkat adopsi inovasi padi sawah organik lebih tinggi.

\section{Faktor-Faktor yang Mempengaruhi Tingkat Adopsi Petani Hidroponik.}

Faktor-faktor yang mempengaruhi adopsi terdiri dari 4 variabel bebas yaitu umur (x1), tingkat pendidikan ( $x 2$ ), lama berhidroponik (x3) dan pendapatan (x4). Hasil regresi linier berganda dapat dilihat pada tabel 2 berikut: nyata terhadap variabel dependent $(Y)$. $\mathrm{Hal}$ ini didukung dengan $u j i \mathrm{~F}$ (anova) yang signifikan (sig< 0,00 ) dan nilai koefisien determinasi $\left(R^{2}\right)$ sebesar 0,586 atau 58,6 \%. Faktor -faktor internal petani (umur,tingkat pendidikan, lama berhidroponik dan pendapatan) berpengaruh secara signifikan terhadap 
JURNAL BORNEO SAINTEK

Volume 3, Nomor 2, Oktober 2020

e-ISSN 2599-3313

P-ISSN 2615-434X

tingkat adopsi sebesar $58,6 \%$ sisanya $41,4 \%$ dipengaruhi faktor lain diluar model yaitu faktor ekternal misalnya sifat-sifat dari inovasi yang diberikan. Model persamaan regresi linier berganda dapat dituliskan pada persamaan sebagai berikut :

$\mathrm{Y}=9,938+1,066 \times 1+2,766 \times 2+1,370 \times 3+$ $0,729 \times 4+e$.

Adopsi merupakan suatu proses yang terjadi pada seseorang ketika menerima suatu inovasi. Proses yang dimaksud merupakan perubahan dari kebiasaan lama menjadi kebiasaan baru,ataupun menolak suatu perubahan. Faktor -faktor yang mempengaruhipun beragam, secara garis besar dibagi menjadi dua yaitu faktor internal (karakteristik petani) dan faktor ekternal (sifat inovasi yang diterima). Semakin tinggi pendidikan didukung usia yang masih produktif akan mempercepat proses adopsi, sedangkan dalam penelitian variabel pendapatan tidak berpengaruh, karena pendapatan rata-rata responden beragam namun tidak mempengaruhi tingkat adopsinya ,rata-rata tingkat adopsi petani dalam kategori tinggi.

Inti dari setiap upaya pembangunan yang disampaikan melalui kegiatanpenyuluhan pada dasarnya ditujukan untuk tercapainya perubahanperubahan perilakumasyarakat demi tercapainya perbaikan mutu hidup yang mencakup banyak aspek, baik ekonomi, sosial, budaya, ideologi, politik maupun pertahanan dan keamanan. Olehkarena itu, pesan-pesan pembangunan yang disuluhkan harus mampu mendorong ataumengakibatkan terjadinya perubahan-perubahan yang memeliki sifat "pembaharuan"yang bisa disebut dengan istilah "inovativeness"(Mardikanto, 2002 dalam Setiawan 2017).

\section{KESIMPULAN}

Proses adopsi yang terjadi pada petani hidroponik di Kecamatan Tarakan Tengah meliputi : Tahap Kesadaran (awareness), Tahap minat (interest), Tahap penilaian ( Evaluation), Tahap mencoba ( trial) dan Tahap adopsi (adoption). Mayoritas tingkat adopsi petani hidroponik di Kecamatan Tarakan Tengah dalam
Available online at www.jurnal.borneo.ac.id Halaman 79-83

kategori tinggi sebesar 49\% (19 responden). Nilai koefisien determinasi $\left(R^{2}\right)$ sebesar 0,586 atau $58,6 \%$, variabel $\mathrm{x} 1, \mathrm{x} 2$ dan $\mathrm{x} 3$ berpengaruh signifikan terhadap variabel $Y$ (Tingkat adopsi) sedangkan variabel $x 4$ tidak berpengaruh signifikan.

\section{UCAPAN TERIMA KASIH}

Penulis mengucapkan terimakasih kepada Lembaga Penelitian dan Pengabdian Masyarakat (LP2M) Universitas Borneo Tarakan, atas bantuan bantuan dana penelitian dosen melalui DIPA UBT Tahun 2020.

\section{DAFTAR PUSTAKA}

Harnanik,Sri.2014. Keragaan Adopsi Teknologi pada Pelaksanaan MKRPL di Tiga Lokasi Kota Prabumulih, BPTP Sumatera Selatan.

Iqbal, M. 2009. Rancang Bangun Sinergi Kebijakan Agropolitan dan Pengembangan Ekonomi Lokal Menunjang Percepatan Pembangunan Wilayah. Jurnal Analisis Kebijakan Pertanian. Volume 7 (2).

Setiawan dan Astiti 2017. Faktor-Faktor yang Mempengaruhi Adopsi Inovasi Sistem Tanam Jajar Legowo 2:1 di Subak Penyaringan Kecamatan Mendoyo Kabupaten Jembrana. Jurnal Manajemen Agribisnis Volume 5 (2).

Sugiyono, 2013. Statistika Untuk Penelitian, Penerbit Alfabeta,Bandung.

Suroyo, B dan Handayani, W.2014. Pengembangan Kawasan Agropolitan di Kabupaten Kulonprogo, Daerah Istimewa Yogyakarta. Jurnal Perencanaan Wilayah dan Kota. Vol 25 (3).

Wangke dan Susana 2016. Adopsi Petani Terhadap Inovasi Tanaman Padi Sawah Organik di Desa Molompor Kecamatan Tombatu Timur, Kota Minahasa Tenggara. Jurnal Agri Sosio Ekonomi Unsrat Vol 12 (2). 